and fourth days, the differential training groups received three $\mathrm{CS}+$ trials paired with shock, and three CS presentations never paired with shock. Nondifferential Ss continued to receive only three reinforced CS+ trials on each of the last 2 days of training. No stimulus presentations were made during the session following the completion of training in order to allow bar-pressing baselines to recover.

Extinction began on the next session. For the differentially trained $S s$, four extinction trials of CS+ were scheduled daily, until the .20 criterion was satisfied. On the next trial, a CS- was presented, followed by a test trial on which CS+ was presented for half the Ss and the $\mathrm{CS}+/ \mathrm{CS}$ - compound for the other half.

On the following day, CS+ was presented again. When the .20 criterion was met within four trials, a $\mathrm{CS}$ - trial followed, in turn succeeded by either $\mathrm{CS}+$ or $\mathrm{CS}+/ \mathrm{CS}-$, whichever had not been tested on the previous day. The same procedure served for the nondifferential group, with $\mathrm{CS}^{\circ}$ replacing $\mathrm{CS}-$.

\section{Results}

Both groups of Ss showed almost complete suppression by the second day of acquisition. No significant suppression to the $\mathrm{CS}$ - occurred when it was introduced on Day 3 of acquisition. By Day 4, however, differential Ss exhibited significant acceleration to $\mathrm{CS}$ - (median Day $4 \mathrm{CS}-$ ratio $=.56, \quad$ Wilcoxon $\mathrm{T}=2, \mathrm{n}=11$, $\mathrm{p}<.01$ ), indicating that $\mathrm{CS}-$ had an effect on responding different from that of the background stimuli.

The results of both test blocks for the differential and nondifferential groups are shown in the lower section of Fig. 1. The three points on each curve represent the CSt criterion trial, the subsequent $\mathrm{CS}-$ or $\mathrm{CS}^{\circ}$ trial, and the tests of either CS+ or the appropriate compound. For all $S$ s in the differential group, the compound produced less suppression than the test $\mathrm{CS}+$ (Wilcoxon $t=6.5, n=11, p<.05$ ); for Ss in the nondifferential group, there was no significant difference between compound and test CSt. Furthermore, the magnitude of the difference between test CS+ and compound was significantly greater for differential Ss than for nondifferential Ss (Mann-Whitney $U=26.5, n=21, p<.05$ ).

$$
\text { DISCUSSION }
$$

When the results of the two experiments are combined, they indicate that (1) two $\mathrm{CS}+\mathrm{s}$, when presented in compound, produce more suppression than either alone; (b) a CSt and a CS-, when presented in compound, produce less suppression than the CSt alone; and (c) a compound consisting of CSt and a "neutral" $\mathrm{CS}^{\circ}$ produces suppression which does not differ from CS+ alone. Furthermore, these results were obtained after relatively little training, in contrast to other experiments which studied compounds of CS+s (Miller, 1969) and of a CSt and CS- (Hammond, 1967) after extensive single-stimulus training.

These data indicate that the same results are obtained for compounds of classically conditioned stimuli as for compounds of operantly conditioned stimuli (Comell \& Strub, 1965). Furthermore, the inclusion of the $\mathrm{CS}+/ \mathrm{CS}^{\circ}$ compound in the present experiment permits one to rule out certain interpretations of the data. The possibility that the effect of either compound stimulus could be accounted for by some "novelty" effect leading to increased suppression, or generalization decrement leading to decreased suppression, is not supported by the outcome of the second experiment. Novelty, or generalization decrement, should have led to a change in responding to the $\mathrm{CS}+/ \mathrm{CS}^{\circ}$ compound as well as to the $\mathrm{CS}+/ \mathrm{CS}-$ compound. This did not occur. The simplest and most compelling explanation of the data is that the effect of a compound is produced by some combination of excitatory strengths tending to suppress bar pressing, and inhibitory strengths tending to attenuate the suppression. If this explanation is correct, the compound procedure will permit one to determine the excitatory or inhibitory properties of an unknown stimulus, as do the conditioned-inhibition (Pavlov, 1927; Brown \& Jenkins, 1967) and the generalization of inhibition (Jenkins, 1965) techniques. If it is excitatory, a compound of the unknown stimulus and a CS+ should produce more suppression than either stimulus alone; if it is inhibitory, the compound should produce less suppression than the CS+

\section{REFERENCES}

BROWN, P. L., \& JENKINS, H. M. Conditioned inhibition and excitation in operant discrimination learning. Journal of Experimental Psychology, 1967, 75, 255-266. COR NELL, J. M., \& STRUB, H. A technique for demonstrating the inhibitory function of $S \Delta$ Psychonomic Science, 1965, 3, 25-26.

HAMMOND, L. J. A traditional demonstration of the active properties of Pavlovian inhibition using differential CER. Psychonomic Science, 1967, 9, 65-66.

JENKINS, H. M. Generalization gradients and the concept of inhibition. In D. J. Mostofsky (Ed.), Stimulus generalization. Stanford: Stanford University Press, 1965.

MILLER, L. Compounding of pre-aversive stimuli. Journal of the Experimental Analysis of Behavior, 1969, 12, 293-299.

PAVLOV, I. P. Conditioned reflexes. London: Oxford University Press, 1927. NOTES

1. The research described in this paper was supported by funds from Research Grants No. 258 from the Ontario Mental Health Foundation and No. APA 42 from the National Research Council of Canada to A. H. Black. We thank Mrs. H. Santa-Barbara for her editorial assistance.

2. Examination of VI baselines turoughout the conditioning and extinction sessions revealed no systematic difference which could account for the test trial outcomes. This was also true of the second experiment.

\title{
Conditioned suppression on a fixed interval schedule of reinforcement ${ }^{1}$
}

DAVID O. LYON and RICHARD D. MILLAR, Westem Michigan University, Kalamazoo, Mich. 49001

The key-pecking behavior of two pigeons was maintained on a 2-min fixed-interval schedule of reinforcement. The interval was divided into four 30-sec periods, and an Estes-Skinner conditioned-suppression procedure was superimposed on the second, third, and fourth 30-sec periods of the fixed interval. Suppression was obtained during the second 30-sec interval, but a complete loss of suppression was obtained when the CS was presented during the last 30-sec period prior to a reinforcement. The results serve to complete the generalization that the severity of conditioned suppression on fixed schedules of reinforcement is determined in part by the temporal relationship between the CS onset and the presentation of a reinforcement.

The present study was designed to measure changes in the severity of conditioned suppression as a function of the placement of the preshock stimulus within a fixed-interval schedule of reinforcement. The behavioral effect of conditioned suppression is defined as a decrease in the rate of a positively reinforced response during a stimulus (CS) which precedes shock (Estes \& Skinner, 1941). The defining characteristic of the procedure is that the stimulus and shock are superimposed on the baseline independently of the baseline performance. 


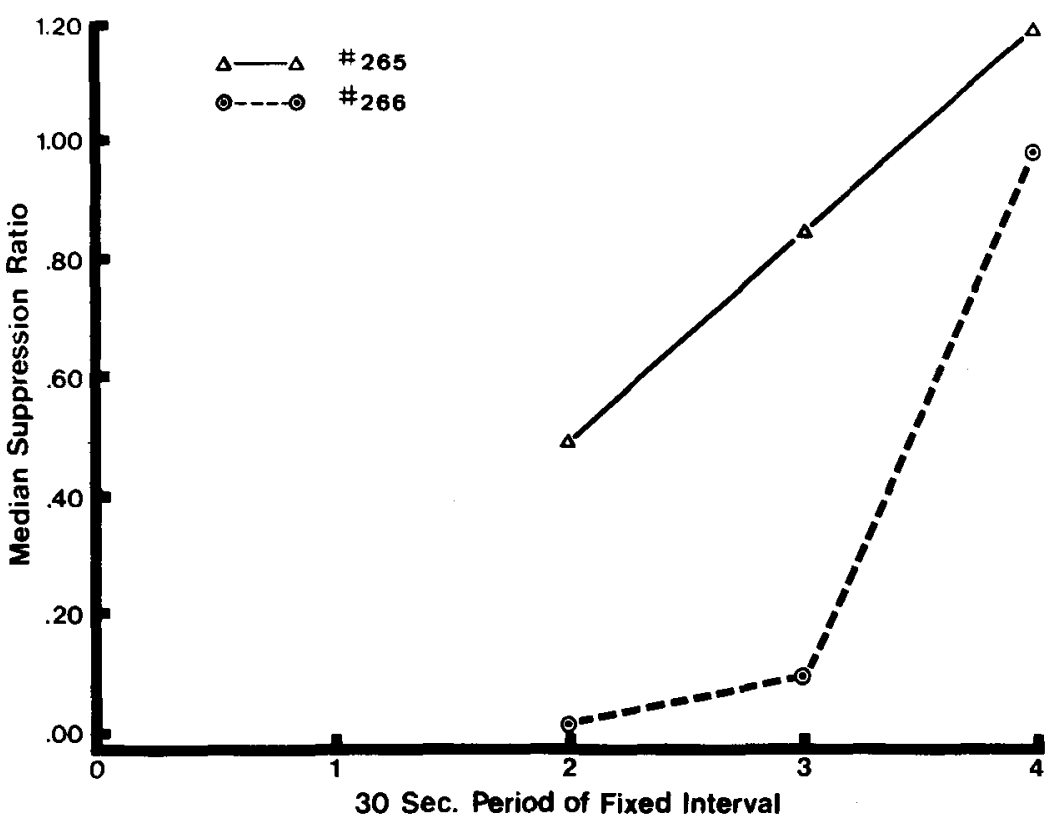

A number of recent studies have indicated that the severity of the suppression effect is determined in part by the reinforcement variables used to maintain the baseline behavior, including the type (Geller, 1960; Brady \& Conrad, 1960), schedule (Brady, 1955; Lyon, 1964; Lyon \& Felton, 1966a, b), and frequency (Lyon, 1963) of reinforcement. In particular, when reinforcements are programmed according to a fixed-ratio schedule (Lyon, 1964; Lyon \& Felton, 1966a), the animals display complete suppression if the preshock stimulus immediately follows reinforcement. When the preshock stimulus immediately precedes reinforcement, however, the animals continue to respond until reinforcement is obtained and then display complete suppression. Thus, the severity of suppression is directly related to the placement of the $C S$ within the ratio run.

The purpose of the present study was to determine if a similar relationship between suppression and the placement of the CS would be obtained when reinforcements were programmed according to a fixed-interval schedule of reinforcement.

\section{METHOD}

Two white Carneaux barren hen pigeons were maintained within $10 \mathrm{~g}$ of $75 \%$ of their free-feeding weights.

The pigeon's key-pecking behavior was maintained on a fixed-interval 2-min schedule for a $4 \mathrm{sec}$ access to grain reinforcement. The session was terminated after 50 reinforcements. The fixed interval was divided into four $30-\mathrm{sec}$ periods. After the key pecking was stable, a 30-sec, 74-dB buzzer was presented periodically, approximately 12 times per session, during the second $30-\mathrm{sec}$ interval of the schedule and terminated coincidentally with shock The 20-msec 50-V ac shock was delivered to permanent wing bands attached to the birds (Hoffman \& Fleshler, 1959). The degree of suppression was measured during the second, third, and fourth 30-sec periods of the interval for a minimum of 10 sessions and until the suppression remained fairly stable from one session to the next. The degree of suppression obtained during the second $30-$ sec period of the interval was then replicated, demonstrating no sequential effects.

\section{RESULTS AND DISCUSSION}

The results were analyzed in terms of the median suppression ratio for the last five sessions under each of the three conditions. The suppression ratio was computed by dividing the rate of response in the CS by the rate of response which occurred during the same 30 -sec period of the fixed-interval schedule in the absence of the CS. It is important to note that neither the mean rate per session nor the rate prior to the CS was used as the denominator. This ratio ranges from .00 , indicating complete suppression, to 1.0 , indicating an equal response rate during the CS and the baseline control period.

The median suppression ratios are presented in Fig. 1 for the two birds, as a function of the period during the fixed interval where the CS onset occurred. The curve describing this function indicates median suppression ratios of and for the two birds during the second period of the fixed interval, and a gradual loss in the severity of suppression as the CS onset was moved
Fig. 1. The median suppression ratio for the two birds as a function of the 30 -sec period during which the CS was presented in the 2-min fixed-interval schedule.

closer to the presentation of the reinforcement.

The results of the present study clearly indicate a functional relationship between the suppression phenomenon and the placement of the CS on a fixed-interval schedule. These data might have been predicted from Azrin's study (1961) indicating less disruption of key pecking by punishment just prior to reinforcement as compared to the initial phases of a fixed interval. The results of the present study, however, serve to complete the generalization (Lyon, 1968) that the severity of a conditioned suppression on fixed schedules of reinforcement is determined in part by the relationship between the CS onset and the presentation of a reinforcement.

\section{REFERENCES}

AZRIN, N. H., \& HOLZ, W.C. Punishment during fixed-interval reinforcement. Joumal of the Experimental Analysis of Behavior, 1961, 4, 343-347.

BLACKMAN, D. Conditioned suppression or facilitation as a function of the behavior baseline. Journal of the Experimental Analysis of Behavior, 1968, 11, 53-61.

BRADY, J. V. The extinction of a conditioned "fear" response as a function of reinforcement schedules for competing behavior. Journal of Psychology, 1955, 40, 25-34.

BRADY, J. V., \& CONRAD, D. G. Some effects of limbic system self-stimulation upon conditioned emotional behavior. Joumal of Comparative \& Physiological Psychology, 1960, 53, 128-137.

ESTES, W. K., \& SKINNER, B. F. Some quantitive properties of anxiety. Journal of Experimental Psychology, 1941, 29, 390-400.

GELLER, I. The acquisition and extinction of conditioned suppression as a function of the base-line reinforcer. Journal of the Experimental Analysis of Behavior, 1960, 3, 235-240.

LYON, D. O. Frequency of reinforcement as a parameter of conditioned suppression. Joumal of the Experimental Analysis of Behavior, 1963, 6, 95-98.

LYON, D. O. Some notes on conditioned suppression and reinforcement schedules. Joumal of the Experimental Analysis of Behavior, 1964, 7, 289-291.

LYON, D. O. Conditioned suppression: Operant variables and aversive control. Psychological Record, 1968, 18, 317-338.

LYON, D. O., \& FELTON, M. Conditioned suppression and variable ratio reinforcement. Joumal of the Experimental Analysis of Behavior, 1966a, 9, 245-248.

LYON, D. O., \& FELTON, M. Conditioned suppression and fixed ratio schedules of reinforcement. Psychological Record, 1966b, $16,433-440$.

NOTE

1. This study was supported by Public Health Service Grant MH 12028-01 